\title{
Determination of a flow center on an ice cap
}

\author{
C.J. VAN DER VEen \\ Byrd Polar Research Center, The Ohio State University, Columbus, Ohio 43210, U.S.A.
}

I. M. WHILLANS

Byrd Polar Research Center and Department of Geological Sciences, The Ohio State University, Columbus, Ohio 43210, U.S.A.

\begin{abstract}
A method for identifying the center of ice flow is developed and applied using results from surveys of a strain grid near the summit of Dunde Ice Cap (central China). Strain rates are used to compute stresses. These are used with a consideration of the balance of forces to compute basal friction. The flow center at the bed occurs where this friction changes sign. For Dunde Ice Cap, the basal flow center nearly underlies the summit.
\end{abstract}

\section{INTRODUCTION}

Ice-drilling programs often seek to obtain continuous core samples from ice-flow centers. The reason is that, assuming the flow center has not shifted in the past, ice at a flow center is not affected by horizontal flow. Opposing arguments are that the theory for predicting the depth-age scale for a flow center is less well-developed than for a flank site (cf. Raymond, 1983; Bolzan, 1985), and there may be confusing horizontal gradients in snow chemistry or amount. However, these issues are often less severe concerns than the possibility of disturbances due to horizontal flow and so ice cores are sought from ice-flow centers.

It is therefore useful to determine the location of flow centers. For a symmetric ice cap, this center is expected to occur at the highest surface elevation, the ice summit. Actual ice caps are usually not symmetric, because there may be a gradient in net accumulation across the ice cap or differences in bed character on either side. For a nonsymmetric ice cap, horizontal tension from one side may be balanced by tension from the other side and ice from beyond the summit may be pulled across. In that case, the flow center and summit are not co-located.

At the surface, the flow center is the point of zero horizontal velocity, separating ice flowing in different horizontal directions. Such points are flow centers in the most rigorous definition and are best determined using measurements of surface velocity. In practice, such measurements can be difficult to obtain with sufficient accuracy. For example, on Dunde Ice Cap $\left(38^{\circ} 06^{\prime} \mathrm{N}\right.$, $96^{\circ} 24^{\prime}$ E; Qilian Shan, China; Fig. 1), the survey traverse across the ice cap from exposed rock is believed to contain an error for one of the measurement epochs and reliable absolute velocities cannot be computed.

The flow center at depth may not be beneath the flow center at the surface. The flow center at the bed is distinguished by being a site of zero basal shearing. If the

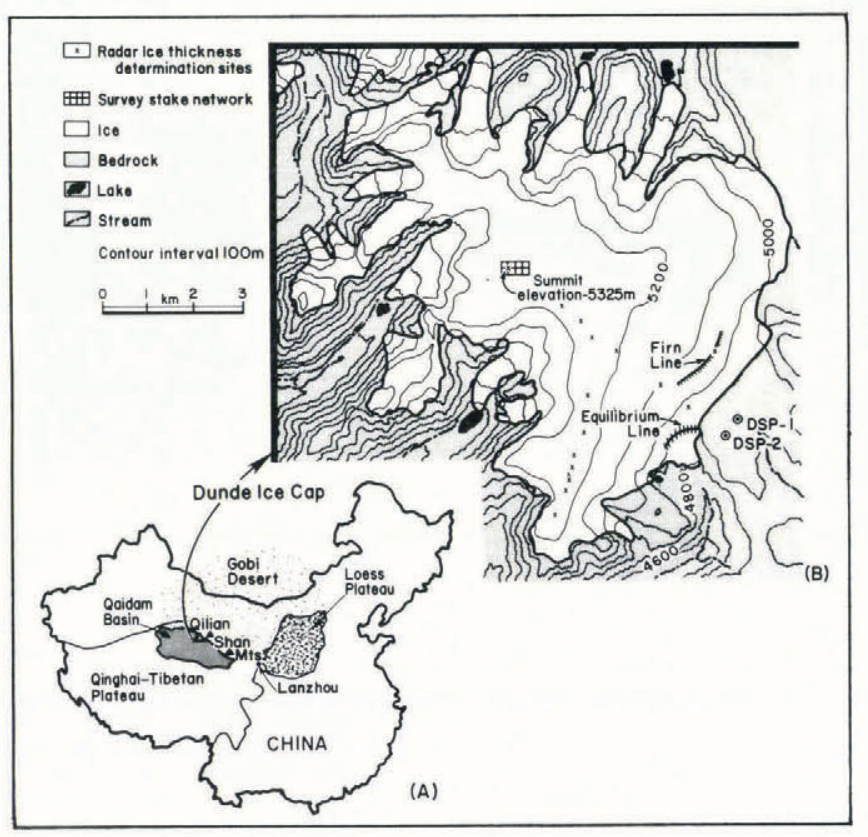

Fig. 1. Dunde Ice Cap location map; from Thompson and others (1990).

reasonable assumption is made that a site of zero shearing is also a site of zero basal drag, the flow center at the bed can be determined from the distribution of basal drag. This is the method adopted here and applied to Dunde Ice Cap.

\section{METHOD AND APPLICATION}

Measured strain rates are used with surface elevations to calculate basal drag. Basal drag follows from a consideration of the balance of horizontal forces acting on a 
column of ice extending from the bed to the surface (Van der Veen and Whillans, 1989):

$$
\begin{aligned}
& \tau_{\mathrm{b} x}=\tau_{\mathrm{d} x}+\frac{\partial}{\partial x}\left(H \bar{R}_{x x}\right)+\frac{\partial}{\partial y}\left(H \bar{R}_{x y}\right) \\
& \tau_{\mathrm{b} y}=\tau_{\mathrm{d} y}+\frac{\partial}{\partial y}\left(H \bar{R}_{y y}\right)+\frac{\partial}{\partial x}\left(H \bar{R}_{x y}\right)
\end{aligned}
$$

where $H$ represents the ice thickness and $\bar{R}_{i j}$ represents the various depth-averaged resistive stresses. The equations show that the components of basal drag, $\tau_{\mathrm{bi}}$, equal the driving stress, $\tau_{\mathrm{di}}$, corrected for differential pushes or pulls (the second term on the righthand side) and for cross-gradients in shear stress (the rightmost term).

If the bed is sloping, there may be a small issue of confusion. The present scheme produces the net drag at the bed $\left(\tau_{\mathrm{b} x}, \tau_{\mathrm{b} y}\right)$, defined with respect to horizontal $(x, y)$ and vertical $(\boldsymbol{z})$ coordinates. This quantity includes not only shear stress but also normal stresses arising from the sloping bed (Van der Veen and Whillans, 1989, equation (9)). In precise terms, the flow center at the bed is a site of zero shear stress as defined in a bed-parallel coordinate system. However, conducting a transformation of coordinate axes, one finds, to first order, that the shear stress in a bed-parallel system is nearly equal to the basal drag $\left(\tau_{\mathrm{b} x}, \tau_{\mathrm{b} y}\right)$ as computed here. Therefore, it is appropriate to use basal drag to identify the basal flow center. In the case of Dunde Ice Cap, the bed is nearly level, and so the issue is moot.

The calculations begin with the horizontal components of driving stress (Whillans, 1987)

$$
\tau_{\mathrm{d} x}=-\rho g H \frac{\partial h}{\partial x}
$$

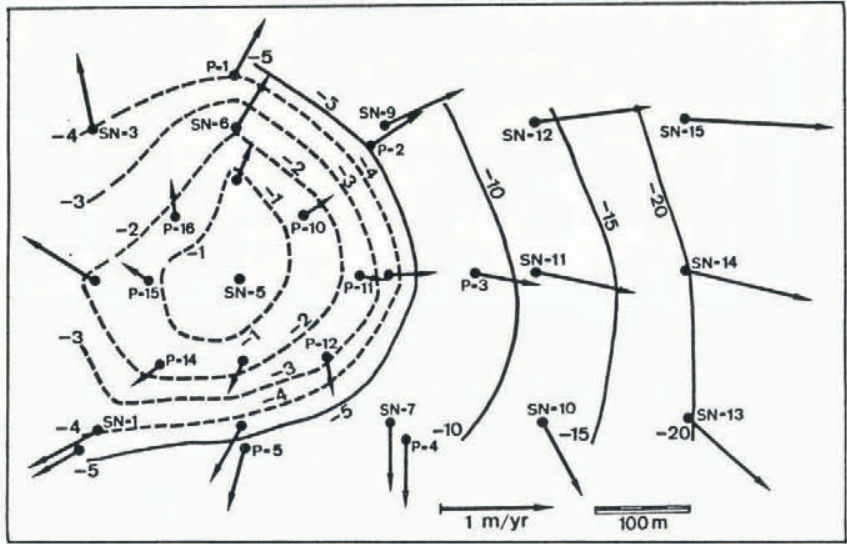

Fig. 2. Elevation contours (contour interval is $1 \mathrm{~m}$ around the ice crest, and $5 \mathrm{~m}$ farther away) and velocity vectors (scale at bottom). Vectors are not perpendicular to elevation contours, probably because of an unresolved rotation of the reference coordinate system.

$$
\tau_{\mathrm{d} y}=-\rho g H \frac{\partial h}{\partial y}
$$

where $\rho$ represents the density of ice, $g$ the acceleration due to gravity and $\partial h / \partial x$ and $\partial h / \partial y$ the components of slope of the ice surface. For Dunde Ice Cap, slopes are calculated from the relative elevations given in Table 1 and plotted in Figure 2. The elevations derive from measurements of vertical angles between neighboring survey poles. Radar measurements show that the ice thickness is nearly constant at $140 \mathrm{~m}$ (Thompson and others, 1988).

Table 1. Survey results for the SN grid. Positions are derived from those listed in Chadwell (1989) by rotating the original coordinate system $-7.09^{\circ}(1986)$ and $-6.99^{\circ}$ (1987) so that for both surveys station $S \mathcal{N}-5$ is the origin, and the $x$-axis passes through station $S \mathcal{N}-8$. Elevations are with respect to station $S \mathcal{N}-5$. Units are meters

\begin{tabular}{|c|c|c|c|c|c|}
\hline SN-1 & -149.73 & -149.98 & -3.88 & -150.06 & -150.16 \\
\hline SN-2 & -150.21 & -0.46 & -1.86 & -150.52 & -0.17 \\
\hline $\mathrm{SN}-3$ & -150.67 & 149.54 & -4.08 & -150.78 & 150.12 \\
\hline SN-4 & 0.22 & -149.62 & -4.37 & -0.01 & -150.02 \\
\hline SN-5 & 0.00 & 0.00 & 0.00 & 0.00 & 0.00 \\
\hline SN-6 & -0.60 & 150.43 & -2.13 & -0.36 & 150.82 \\
\hline SN-7 & 149.90 & -150.17 & -7.00 & 149.87 & -150.67 \\
\hline SN-8 & 149.83 & 0.00 & -3.46 & 150.19 & 0.00 \\
\hline SN-9 & 150.15 & 150.81 & -6.32 & 150.79 & 151.06 \\
\hline SN-10 & 300.41 & -150.15 & -12.08 & 300.69 & -150.72 \\
\hline SN-11 & 299.69 & 0.51 & -10.64 & 300.42 & 0.33 \\
\hline SN-12 & 300.29 & 150.60 & -13.84 & 301.20 & 150.69 \\
\hline $\mathrm{SN}-13$ & 449.97 & -150.12 & -19.70 & 450.61 & -150.71 \\
\hline SN-14 & 448.58 & 1.36 & -19.86 & 449.56 & 1.09 \\
\hline SN-15 & 448.90 & 150.17 & -22.59 & 450.09 & 150.07 \\
\hline
\end{tabular}

$\begin{array}{llllll}\text { Station } & y & \text { Elevation } & x & y\end{array}$




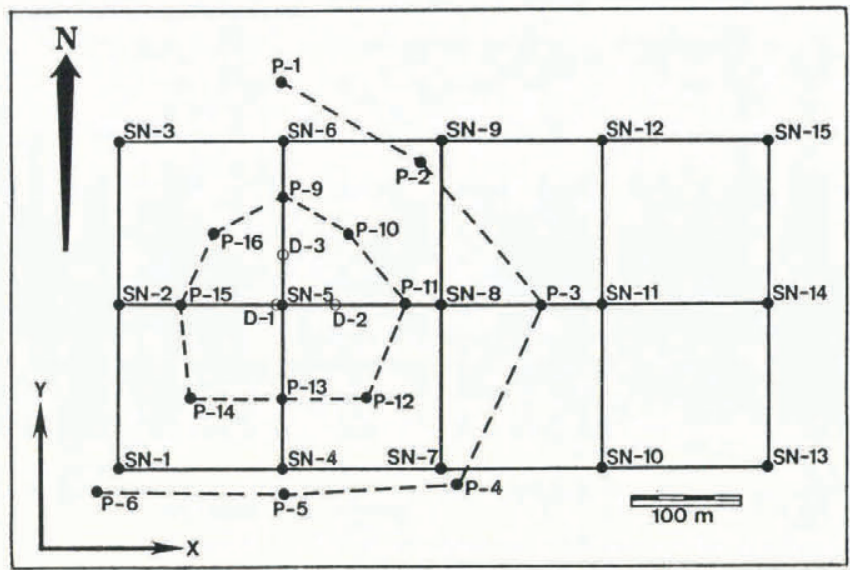

Fig. 3. Circular grid ( $P$ stations) and rectangular grid (SN stations) around the summit of Dunde Ice Cap. The locations of the deep boreholes are shown with three open circles (labelled D-1, D-2 and D-3).

The gradient terms in the balance Equations (1) and (2) are calculated using measured surface strain rates. For this, it is most convenient if data on a regular grid are available. On Dunde Ice Cap, there are two overlapping strain networks (Fig. 3). The first, circular, grid consists of two concentric rings of stations (P-1 to $\mathrm{P}-16$ ) with radii of 75 and $150 \mathrm{~m}$. The data from this strain network are not used here. The second, rectangular, grid (SN-1 to SN-15) consists of a nearly regular matrix of stations three ranks wide and five long, with $150 \mathrm{~m}$ spacing. Data from this grid (presented in Table 1) are adequate to compute basal drag at sites $\mathrm{SN}-5, \mathrm{SN}-8$ and $\mathrm{SN}-11$.

The relative positions of the $\mathrm{SN}$ series of stations are available from two surveys. Because at least one of the surveys is not satisfactorily tied to an absolute frame of reference, we have established a local frame of reference (origin at station $\mathrm{SN}-5, x$-axis passing through station $\mathrm{SN}$ 8). Although this frame may be moving and rotating, it poses no problem for the calculation of force budget, which requires gradients in strain rate. Strain rates are unaffected by translation or rotation of the coordinate system.

Horizontal strain rates $\left(\dot{\varepsilon}_{x x}, \dot{\varepsilon}_{y y}\right.$ and $\left.\dot{\varepsilon}_{x y}\right)$ are taken to be independent of depth. Some assumption is necessary because the grid is too small for the full, more precise force-budget calculations in which their depth variation is calculated explicitly (Van der Veen and Whillans, 1989). By taking horizontal strain rates to be independent of depth, the viscous terms in the force-balance equations are probably overestimated and differences between basal drag and driving stress exaggerated. Thus, the present analysis yields an upper limit to the displacement of the flow center from the ice crest.

Invoking the constitutive relation for ice at $-5^{\circ} \mathrm{C}$ (Hooke, 1981), surface strain rates are used to calculate the (depth-averaged) resistive stresses as needed to solve Equations (1) and (2) for drag at the glacier base. Values of velocity and strain rates are given in Table 2 . The strain rates are used with the flow law to compute stresses, and the stresses are used in an analysis of the force budget on a column of ice to compute basal drag.

Figure 4 shows the basal drag for the three stations for which the calculation is possible. The values of each of the terms in the force budget are given in Table 3. At the station near the summit (SN-5), basal drag is near zero. It is directed at about a $90^{\circ}$ angle from the driving stress, primarily due to the gradient in shear strain rate. At the middle station, $\mathrm{SN}-8$, basal drag is directed more to the south than is the driving stress, mainly because of the pulling action of the ice south of the grid. At the next station (SN-11), basal drag and driving stress are in the same direction, as is assumed in most two-dimensional models of ice flow. Basal drag is significantly smaller than the corresponding driving stress, as a result of both a

Table 2. Velocity (in $\mathrm{ma}^{-1}$ ) and strain rates (in $10^{-3} a^{-1}$ ) at the SN stations

\begin{tabular}{|c|c|c|c|c|c|}
\hline Station & $u_{x}$ & $v_{y}$ & $\dot{\varepsilon}_{x x}$ & $\dot{\varepsilon}_{y y}$ & $\dot{\varepsilon}_{x y}$ \\
\hline SN-1 & -0.379 & -0.206 & - & - & - \\
\hline SN-2 & -0.356 & 0.409 & - & 3.30 & - \\
\hline $\mathrm{SN}-3$ & -0.126 & 0.666 & - & - & - \\
\hline SN-4 & -0.264 & -0.459 & 1.07 & - & - \\
\hline SN-5 & 0.000 & 0.000 & 2.56 & 3.02 & 0.22 \\
\hline SN-6 & 0.275 & 0.448 & 2.86 & - & - \\
\hline $\mathrm{SN}-7$ & -0.034 & -0.574 & 1.95 & - & - \\
\hline $\mathrm{SN}-8$ & 0.413 & 0.000 & 2.80 & 2.86 & 0.93 \\
\hline SN-9 & 0.735 & 0.287 & 2.56 & - & - \\
\hline SN-10 & 0.321 & -0.654 & 2.56 & - & - \\
\hline SN-11 & 0.838 & -0.207 & 2.38 & 2.52 & 0.69 \\
\hline $\mathrm{SN}-12$ & 1.045 & 0.103 & 2.11 & - & - \\
\hline $\mathrm{SN}-13$ & 0.735 & -0.677 & - & - & - \\
\hline SN-14 & 1.125 & -0.310 & - & 1.87 & - \\
\hline SN-15 & 1.366 & -0.115 & - & - & - \\
\hline
\end{tabular}




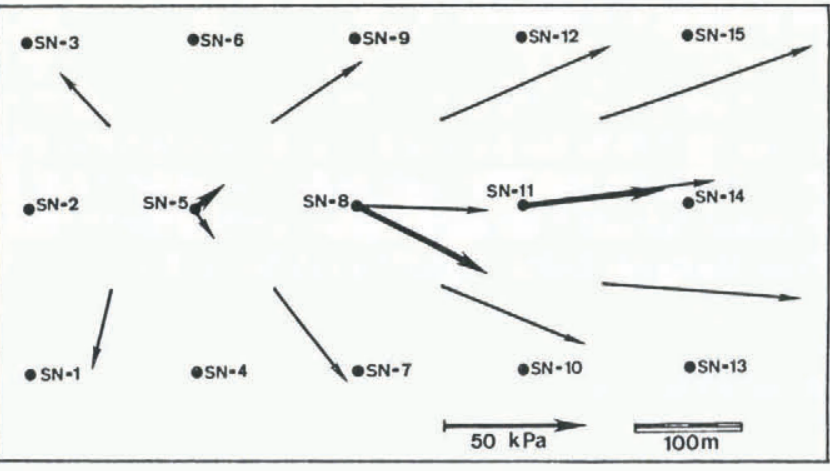

Fig. 4. Driving stress (light arrows) and basal drag (heavy arrows). For ease of comparison, the upper part of each shear couple is shown. The basal force acting on the ice is oppositely directed.

longitudinal force directed up-glacier and a shear force associated with turning of the flowline.

A rough estimate of the location of the basal flow center is possible using these three values of basal drag. A simple interpolation of the $x$-component of the drag shows it passing through zero about $70 \mathrm{~m}$ west of station SN-5. The position of the summit is calculated using linear interpolation of measured surface slope and is about $50 \mathrm{~m}$ west of station $\mathrm{SN}-5$. Considering that the grid spacing is $150 \mathrm{~m}$, the positions of the summit and the basal flow center are indistinguishable. The basal flow center underlies the summit. Thus, modern-day horizontal transport of ice may be neglected in interpreting the results from ice cores taken from the three locations shown in Figure 3 (Thompson and others, 1989).

Strain rates have been assumed to be independent of depth. This is a simple assumption but it could be refined. For example, Raymond (1983) found that the stretching rate, $\dot{\varepsilon}_{x x}$, decreases approximately linearly to zero at the bed, for an ice center in a glacier that is frozen to its bed. If this finding also applies to the other horizontal strain rates, $\dot{\varepsilon}_{x y}$ and $\dot{\varepsilon}_{y y}$, the depth-averaged strain rates would be half those measured at the surface, and the viscous terms in the balance of forces should be multiplied by a factor of 0.8 . The calculated basal drag would then be nearer in value and direction to the driving stress, and the basal flow center even closer to the position of the summit.

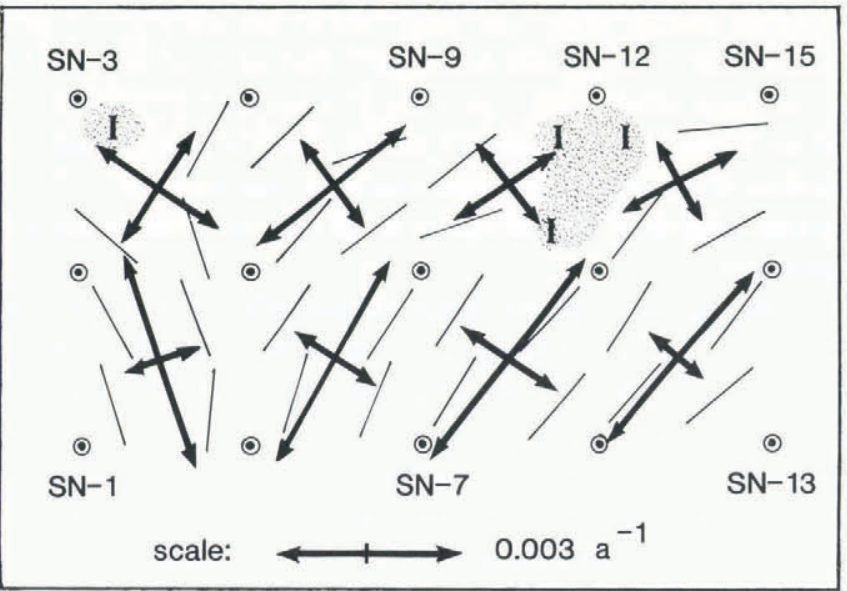

Fig. 5. Principal strain rates (with arrows) calculated for each square in the $S \mathcal{N}$ series of stations. The lines without arrows show the orientations of the maximum principal extending strain rates calculated using triangles in the $S \mathcal{N}$ series. The letters $I$ and stippling indicate sites where the two principal strain rates are nearly equal; these are isotropic points.

\section{ISOTROPIG POINTS}

An interesting issue concerns the nature of the strain-rate pattern around the summit (near station SN-5). The principal strain rates are shown in Figure 5. Tension is larger from the south than from the north. This is surprising, especially as the elevation contours are nearly circular (with an exception at station P-16). Furthermore, the location of the summit is about equidistant from the northern and southern edges of the ice cap (Fig. 1). The reason for the asymmetry in strain rates is not known.

There seem to be isotropic points in strain rate; they are labeled in Figure 5. These are sites where the two horizontal principal strain rates are equal (and their orientation undetermined) (Nye, 1983). Isotropic points are important in classifying the type of flow. Because the strain grid does not completely surround suspected isotropic points, the presence of the isotropic points is probable but not certain.

The simplest model for a flow center (uniform ice thickness, constant accumulation rate, steady flow)

Table 3. Budget of forces at the three center stations of the rectangular $S \mathcal{N}$ grid (units, $k P a$ )

\begin{tabular}{|c|c|c|c|c|c|c|c|c|}
\hline \multirow[b]{2}{*}{ Station } & \multicolumn{4}{|c|}{$x$-direction } & \multicolumn{4}{|c|}{$y$-direction } \\
\hline & $\tau_{\mathrm{d} x}$ & $\tau_{\mathrm{b} x}$ & $\partial\left(H \bar{R}_{x x}\right) / \partial x$ & $\partial\left(H \bar{R}_{x y}\right) / \partial y$ & $\tau_{\mathrm{d} y}$ & $\tau_{\mathrm{b} y}$ & $\partial\left(H \bar{R}_{y y}\right) / \partial y$ & $\partial\left(H \bar{R}_{x y}\right) / \partial x$ \\
\hline SN-5 & 6.7 & 9.4 & 2.7 & 0.0 & -9.4 & 5.4 & -0.6 & 15.4 \\
\hline SN-8 & 44.7 & 43.2 & 1.6 & -3.0 & -2.8 & -22.6 & -15.5 & -4.3 \\
\hline SN-11 & 69.1 & 48.7 & -9.6 & -10.8 & 7.4 & 4.3 & -6.4 & 3.3 \\
\hline
\end{tabular}


predicts strain rates that are everywhere isotropic. This is unlikely to be found in Nature and it does not apply here. Nye (1991) studied second-order perturbations to strain rates on this simplest model. In Nye's perturbation model, there should be two isotropic points near a flow center and they should both be of the type classified as lemons.

The isotropic point near station $\mathrm{SN}-12$ could be a lemon or a monstar because the trajectories of maximum extending strain rate converge on approaching it. Wider coverage for strain rate is needed to classify this point more precisely. The isotropic point near station $\mathrm{SN}-3$ is a star, because the trajectories diverge on approaching it. This isotropic point does not fit Nye's prediction.

A similar analysis of strain rate on Quelccaya Ice Cap, Peru (Chadwell, 1989) (not shown here), shows just one isotropic point near the summit. It is a star. The flow centers on Dunde and Quelccaya Ice Caps are much more complex than the simple perturbation theory used by Nye (1991) describes.

\section{CONCLUSION}

The result that the basal flow center underlies the summit of Dunde Ice Cap may not be automatically extended to other summits. Haefeli (1963) (also discussed by Paterson (1981, p. 159)) showed that, for a glacier on Jungfraujoch, Switzerland, the ice flow at depth appears to be affected by the slope of the base, and the flow center is not in the same location as the summit. The two are close together on Dunde Ice Cap, presumably because any asymmetry of form and flow around the summit is minor and does not greatly displace the flow center.

The position of flow centers is usually considered important to the analysis of ice cores. The measurement program to locate the flow center, using the method described here, is cheap and simple and should be conducted around every deep core site. Consideration needs to be given to the proper design of the strain grid. The rectangular SN grid established on Dunde Ice Cap is barely adequate for calculating basal drag using the force-budget technique. Only three values could be determined. Ideally, the survey grid should be more than three stations wide to allow for determination of the north-south coordinate of the flow center, and it should extend farther to the west of the summit to allow calculation of basal drag on all sides of the summit. Strain-network design has been discussed further in Whillans and Van der Veen (1989). The station spacing is approximately equal to the ice thickness, as is appropriate. On glaciers with a more complex flow regime, tying in the strain grid to local rock outcrops would be helpful in locating the site of the surface-flow center. Of course, we are well aware that the ideal can rarely be achieved in the field, especially at the end of such an extended line of logistics as on Dunde Ice Cap.

\section{ACKNOWLEDGEMENTS}

We thank H. Brecher, J.F. Nye and L. Thompson for numerous discussions on, especially, data reliability, and the referees for valuable suggestions. Supported by U.S. National Science Foundation grant DPP-8716447; Byrd Polar Research Center Contribution No. 715.

\section{REFERENCES}

Bolzan, J.F. 1985. Ice flow at the Dome C ice divide based on a deep temperature profile. 7. Geophys. Res., 90(D5), 8111-8124.

Chadwell, C. D. 1989. Determining the surface velocities of the Quelccaya and Dunde Ice Caps. (M.S. thesis, Ohio State University.)

Haefeli, R. 1963. Observations in ice tunnels and the flow law of ice. In Kingery, W. D., ed. Ice and snow; properties, processes, and applications. Cambridge, MA, M.I.T. Press, 162-186.

Hooke, R. LeB. 1981. Flow law for polycrystalline ice in glaciers: comparison of theoretical predictions, laboratory data, and field measurements. Rev. Geophys. Space Phys., 19(4), 664-672.

Nye, J. F. 1983. Monstars on glaciers. F. Glaciol., 29(101), 70-77.

Nye, J.F. 1991. The topology of ice-sheet centres. F. Glaciol., 37(126), 220-227.

Paterson, W.S.B. 1981. The physics of glaciers. Second edition. Oxford, etc., Pergamon Press.

Raymond, C.F. 1983. Deformation in the vicinity of ice divides. F. Glaciol., 29(103), 357-373.

Thompson, L. G., Wu Xiaoling, E. Mosley-Thompson and Xie Zichu. 1988. Climatic records from the Dunde Ice Cap, China. Ann. Glaciol., 10, 178-182.

Thompson, L.G. and 9 others. 1989. Holocene-Late Pleistocene climatic ice core records from QinghaiTibetan Plateau. Science, 246(4929), 474-477.

Thompson, L. G. and 9 others. 1990. Glacial stage ice-core records from the subtropical Dunde Ice Cap, China. Ann Glaciol., 14, 288-297.

Van der Veen, C.J. and I. M. Whillans. 1989. Force budget: I. Theory and numerical methods. F. Glaciol., 35(119), 53-60.

Whillans, I. M. 1987. Force budget of ice sheets. In Van der Veen, C.J. and J. Oerlemans, eds. Dynamics of the West Antarctic ice sheet. Dordrecht, D. Reidel Publishing Co., 17-36.

Whillans, I. M. and C.J. van der Veen. 1989. Design of strain networks: experience from glaciology. In Proceedings. 5th International Geodetic Symposium on Satellite Positioning. Las Cruces, New Mexico, March 13-17, 1989, 842-848.

The accuracy of references in the text and in this list is the responsibility of the authors, to whom queries should be addressed. 